\title{
Bullying and Hazing Among Norwegian Army Soldiers: Two Studies of Prevalence, Context, and Cognition
}

\author{
Kristina Østvik \\ Child \& Youth Psychiatry Clinic \\ Sandnessjøen Hospital \\ Sandnessjøen, Norway \\ Floyd Rudmin \\ Department of Psychology \\ University of Troms $\phi$ \\ Tromsф, Norway
}

\begin{abstract}
Two questionnaire studies examined the social and cognitive contexts of bullying among conscripts in the Norwegian Army. Replicated prevalence was $12 \%$. Study 1 ( $N=696$ soldiers) found that (a) bullying requires familiarity, (b) victims' and witnesses' explanations accord with the Fundamental Error of Attribution, (c) bullying is confounded with hazing, (d) high-risk groups include 18-year-olds and socially-isolated soldiers, and (e) cohort assignment increases bullying. Study $2(N=88$ soldiers, 77 officers) found that (a) soldiers and officers agree that bullying is a problem, (b) beliefs about bullying are unrelated to experience with bullying, (c) soldiers blame the victim more than did officers, (d) officers more often intervene to stop bullying when they blame the victim, and (e) soldiers less often intervene when they blamed the victim. These findings weigh against clinical or personality-trait theories of bullying and argue for organizational and cognitive management of bullying.
\end{abstract}

Bullying entails a physically or socially more powerful person, or group of people, intentionally harassing or hurting a weaker person by physical, verbal, social, or

Requests for reprints should be sent to Kristina Østvik, Child \& Youth Psychiatry Clinic, Sandnessjøen Hospital, Sandnessjøen, Norway N-8801. 
psychological means. Some theorists add further definitional criteria that the harassment must be repeated over an extended period of time (Olweus, 1992). Unlike other forms of interpersonal conflict within social institutions, bullying, by definition, is not instrumental aggression. Bullies have no specific objectives that, if achieved, would end the aggression. Also, by definition, bullying is not random aggression because it is directed at specific target victims. Thus, bullying is deliberate, directed behavior, but it is not goal directed in the usual sense.

Most research on bullying, beginning with Burk's (1897) study, has focused on its moral and developmental implications for schoolchildren, especially in societies in which bullying affronts egalitarian principles of individual rights and social justice, for example, in Scandinavia (Batsche \& Knoff, 1994; Heinemann, 1973; Olweus, 1973; Rigby \& Slee, 1993; Rivers \& Smith, 1994; Roland \& Munthe, 1989; Siann, Callaghan, Glissov, Lockhart, \& Rawson, 1994; Slee, 1994; Smith \& Sharp, 1994). Many studies have sought to describe personality differences between victims and bullies, including differences in their relationships with their parents (Bowers, Smith, \& Binney, 1994; Olweus, 1992; Strassberg, Dodge, Pettit, \& Bates, 1994).

However, bullying also happens among adults. Bullying not only hurts its victims, but it also hurts the coherence and productivity of organizations. Some self-report studies have found 1-year prevalence rates of bullying in the workplace to be 50\% and higher (Quine, 1999; Rayner, 1997). Part of the cost of bullying is increased illness (Einarsen, Raknes, Matthiesen, \& Hellesoy, 1996; Williams, Chambers, Logan, \& Robinson, 1996), especially stress-related illnesses like depression and anxiety (Quine, 1999). Bullying among adults in work organizations has become a topic of interest both for public media and for psychological research (Ashforth, 1994; Einarsen, 1996; Leymann, 1987; Rayner \& Hoel, 1997). Terms other than bullying have been used, including scapegoating, workplace trauma, and mobbing. Various definitions have been proposed—usually emphasizing the continuity of harassment over time and the imbalance in power between the bullies and the victims (Adams, 1992; Leymann, 1990). Most research has descriptively documented bullying and its consequences.

Hazing is another form of interpersonal aggression endemic to organizations; however, it has rarely been discussed in psychological literature. Hazing can be defined as initiation rituals by which newcomers to an organization are harassed and humiliated as a test or preparation for acceptance into the group (Bersani, Nesci, \& Pozzi, 1980). It is easy for aggressors, victims, witnesses, administrators, and researchers to confound bullying and hazing because particular acts of bullying and hazing may be identical, bullying may be rationalized as hazing, and the differentiation of bullying and hazing requires information not always evident in a particular act. Hazing can be differentiated from bullying in the following ways: (a) Hazing is harassment by a cohort of senior members of a group against a cohort of newcomers to the group, whereas bullying is harassment by one or a few indi- 
viduals against isolated individuals; (b) thus, hazing tends to be a public activity, whereas bullying tends to be a private activity; (c) newcomers and subordinates can never haze seniors and superiors, but they can bully them; (d) hazing is ritualistic with little change year after year, whereas bullying is not so constrained and can be quite original in its methods; (e) hazing will terminate at the end of the initiation period, whereas bullying continues indefinitely; (f) hazing eventually brings the victims into group solidarity with their tormentors, whereas bullying excludes the victim from group solidarity; and (g) hazing may be used by organizations as a means of socializing newcomers and enhancing collective morale, whereas bullying threatens organizations because it damages collective morale and is a form of insubordination that competes with legitimate lines of authority. If bullying was used by administrators as a means of controlling a population-for example, in a prison or an occupied territory - then bullying would have been sublimated into instrumental aggression.

It is natural that military organizations, as social institutions, would also experience hazing and bullying. These behaviors in the military should be of serious concern because young men are isolated from moderating social norms and institutions, are being trained for violence, and have access to weapons and heavy equipment. Further aggravating the soldiers' situation, they are not free to leave the organization if they feel abused. In fact, serious incidents of hazing and bullying, sometimes resulting in death or suicide, have been reported from armies around the world (Bivens, 1995; Cermak, 1992/1997; Cvrcek, 1992/1997; Dyomin, 1998; Fisher, 1995; Hytten \& Tande, 1985; Lenny, 1949; McCoy, 1995; Sodownik \& Fok, 1997; Walsh, 1998; Wilcox, 1997). In volunteer armies, bullying has been shown to make recruitment and reenlistment more difficult (Walsh, 1997). In the conscription armies of liberal democratic nations such as Norway, bullying is a form of unjust punishment because victims are coerced by law into a situation of being bullied.

Despite the expectation and the evidence that military units, like other organizations, have problems with bullying and hazing, there have been few, if any, systematic social science studies of this reported in the mainstream research literature. This lack of research is surprising, given that the United States and the United Kingdom overwhelmingly dominate the social science fields, and both countries have large standing armies that are publicly accountable. It is also surprising given that the Scandinavian countries have liberal, egalitarian traditions of enhancing human welfare and are leaders in research on bullying in the school and in the workplace; yet, these countries also conscript their young men into military service where some suffer from bullying and hazing. The goal of this study is to begin to establish a social science literature on this topic by studying bullying and hazing on one army base in Norway. Our hope is that this study will inspire other studies-as replications, extensions, or critiques-within other national armies or comparatively across several national armies. 
The reasoning underlying the two studies presented here follows the trend away from personality theory and clinical explanations and toward social cognitive theory (Arora, 1996; Madsen, 1996; Maines \& Robinson, 1998; Schuster, 1996; Sutton, Smith, \& Swettenham, 1999). Social contexts and cognitions, unlike personality traits, can be modified and entail no stigmatizing presumptions of psychopathology. In addition, effective interventions by administrators will require information about the contexts and cognitions of bullying and hazing within their specific organizations. The traditional readiness to see the causes of bullying in the personality dynamics of victims and bullies is, itself, an instance of a bias in social cognition known as the Fundamental Error of Attribution (FEA; Ichheiser, 1949; Ross, 1977). FEA is the tendency to underestimate the importance of the situation when explaining behavior and to overestimate the importance of the personality traits and motivations of the participants. This bias in social perception presumably distorts the thinking of bullies, victims, bystanders, administrators, and researchers. For this reason, these two studies focus explicitly on the physical, social, and cognitive contexts of bullying and hazing.

\section{STUDY 1}

\section{Purpose}

The first study was a phenomenological exploration of bullying and hazing among soldiers in the Norwegian Army. To be as objectively descriptive as possible, this study surveyed the soldiers' own perceptions and explanations of bullying and hazing, according to their own use of these terms. Following Norwegian practice, soldiers refers only to privates; others with any rank will be referred to as officers.

\section{Method}

Instrument. The one-page research questionnaire, written in Norwegian, first inquired about duration of service, type of military unit, gender, age, and category of service. If soldiers had witnessed bullying or had been victims of bullying themselves, they were asked to choose among five types of relationships between the bully and the victim and among six locations where it happened. The victims of bullying were also asked to report whether it occurred early or late in their course of service and whether the bullies had been their barrack mates. Soldiers were also asked if they had been bullied earlier in life, if they had a friend during the first month of their service, with whom they spent their leisure time, and if they believed that most soldiers haze new recruits. Four spaces were provided for open-ended de- 
scriptions of what happened if the respondent had (a) witnessed bullying, (b) been bullied, (c) been hazed, or (d) hazed others.

No definitions of bullying or hazing were imposed on the participants because the intention of the study was to objectively understand the soldiers' own perceptions and classifications of these phenomena. Soldiers were not asked if they had been bullies because it was considered unethical to seek self-incriminating responses. The questionnaire was approved by military psychologists and administrative staff at the base.

Procedure. One thousand questionnaires were distributed to one third of the soldiers in each of the 12 military units in Bardufoss, Norway. Within each unit, officers decided which groups would receive the questionnaire, which may have biased the sample toward an underestimation of bullying. The most frequently reported selection criteria were practical concerns, such as, "other troops being busy at that time," or "this troop has not participated in other surveys."

With the questionnaire came an envelope and an instruction page explaining that participation was voluntary and anonymous, the questionnaire was to be returned in a sealed envelope, and it was permissible to return an unanswered questionnaire. Soldiers' names were not recorded at any point during the distribution, response, or return of the questionnaires.

Sample. The return rate differed for the 12 units, ranging from $40 \%$ to $100 \%$. Only $8(1 \%)$ of the questionnaires were returned blank, $696(70 \%)$ were returned completed, and the remaining 296 (29\%) were not returned. Of those answering, 666 were men, 14 were women, and 16 were unidentified. Mean age of the sample was 20 years of age, ranging from 18 to 27 years old; $94 \%$ of the sample was 19 to 22 years old. At the time of the survey, $81 \%$ of the soldiers had spent between 9 and 12 months in the Army and were, thus, nearing the end of their compulsory 1-year service. Sixty-five percent had continued with their training cohort according to Norway's new assignment practice of unit replacement, $28 \%$ had been sent to different units according to Norway's old assignment practice of individual replacement, and $7 \%$ did not report on their assignment.

\section{Results and Discussion}

Prevalence of bullying. A total of $81(12 \%)$ respondents reported that they had been bullied by other soldiers in the Army, and 373 (53\%) reported that they had witnessed bullying in the Army. These retrospective reports by victims and witnesses may or may not refer to the same events. A total of $230(33 \%)$ soldiers reported that they had been bullied earlier in life. That experience was weakly correlated with being bullied in the Army, $r(672)=.13, p<.001$, and with witnessing 
bullying in the Army, $r(672)=.13, p<.001$, which suggests that prior experience with bullying sensitizes people or makes them more likely to report bullying.

Of the 230 young adults in this study who reported that they had been bullied in earlier contexts, $82 \%$ of them were not revictimized in the Army. Of the 81 young adults who were bullied in the Army, 50\% of them had never been bullied before. These facts all argue strongly against beliefs and theories that bullying is somehow caused by the victim's personality, mannerisms, habits, speech, looks, body type, or other enduring traits that would be constant in all contexts.

Contexts of bullying. The question of when bullying happened was answered by only $28 \%$ of the victims: 3 people reported that it had happened in the first 6 weeks of service, 10 people between 6 weeks and 7 months, and 10 people after 7 months. Other studies have also found that bullying is less likely to occur when people are unfamiliar with their social context or with each other (Lewin, 1939/1997b; Power, Dyson, \& Wozniak, 1997). However, the evidence here, based on retrospective reports, is tentative because there appear to be memory recency effects.

The location of where bullying took place was reported by $91 \%$ of the victims and $92 \%$ of the witnesses. The relationship of the bully to the victim was reported by $98 \%$ of the victims and $99 \%$ of the witnesses. Thus, retrospective or reconstructive memory of bullying seems weakest for when it happened, better for the setting where it happened, and best when referring to the people who were involved. The reasons for this are open to question.

Victims and witnesses independently reported diverse and self-selected incidents of bullying, sometimes referring to single events and sometimes to multiple events. Nevertheless, their collective reports show the same general patterns. First, $63 \%$ of the victims and $62 \%$ of the witnesses reported bullying in the barracks, and $49 \%$ of the victims and $59 \%$ of the witnesses reported that it had occurred during daytime service. Bullying during field maneuvers was reported by $32 \%$ of the victims and by $29 \%$ of the witnesses. Reports of bullying in the public dining room came from $21 \%$ of the victims and $20 \%$ of the witnesses, and in the after-hours cantina, from $9 \%$ and $11 \%$, respectively. Finally, $7 \%$ of the victims and $8 \%$ of the witnesses selected a miscellaneous category of bullying happening elsewhere.

There was similarly strong concordance between victims' and witnesses' reports about the relationship of the bullies to the victims. First, 58\% of the victims and $67 \%$ of the witnesses reported that the bullies came from the victim's own troop, and $23 \%$ and $25 \%$, respectively, reported that the bullies came from the victim's own unit in the troop. A high degree of familiarity or intensity of contact between bullies and victims is shown further by the fact that $48 \%$ of the victims and $41 \%$ of the witnesses reported that bullying was done by the victim's own roommates. Only $12 \%$ of the victims and $8 \%$ of the witnesses reported that the bullies 
came from another unit, and a mere $1 \%$ of the victims and $1 \%$ of the witnesses reported that they did not know the bullies' relationship to the victim. Clearly, bullying is a function of familiarity or frequency of contact, as shown by the fact that bullies are known to the victims and the witnesses and are known to come from the victim's own operational unit or living quarters.

The concordance between victims' and witnesses' collective reports for the six location categories, $r(6)=.98, p<.01$, and for the five bully categories, $r(5)=.98$, $p<.01$, is a basis for confidence in the reliability of these reports. The high similarity between victims' and witnesses' reports would also arise if some victims were presenting themselves as witnesses because they were hesitant to admit to being victims of bullying. If this were happening to any great extent, then the prevalence rate reported here would be an underestimation.

Of particular concern is that bullying was reported during field maneuvers, where it would seem most dangerous due to the availability of weapons and heavy equipment and where it would risk degrading the performance of individual soldiers and whole military units. Considering that maneuvers account for relatively little of a soldier's total service time, the rate of bullying per unit of time may be higher during maneuvers than during routine base activities.

Descriptions of bullying. Descriptions of bullying incidents were written by 71 victims, comprising $86 \%$ of the total 81 victims, and by 297 witnesses, comprising $80 \%$ of the total 373 witnesses. These open-ended reports were coded into post hoc categories of perceived acts of bullying and perceived causes of bullying. Two independent Norwegian coders each categorized victims' and witnesses' accounts separately, and disagreements between coders were resolved by discussion.

Eight general types of bullying were identified in these descriptions. Verbal and psychological abuse was mentioned by $31 \%$ of all victims and $34 \%$ of all witnesses. Indirect harm, such as slander, was mentioned by $9 \%$ of the victims and $7 \%$ of the witnesses. Forms of physical assault were mentioned by $9 \%$ of the victims and $8 \%$ of the witnesses, and property damage was mentioned by $7 \%$ and $4 \%$, respectively. Bullying was described as harassment by $7 \%$ of the victims and $5 \%$ of the witnesses; as practical jokes by $5 \%$ and $3 \%$, respectively; as hazing by $2 \%$ and $3 \%$, respectively; and as sexual harassment by $1 \%$ of both victims and witnesses. That some soldiers used the Norwegian word for hazing, when asked to describe bullying, demonstrates that these behaviors can be confounded. Victims and witnesses, independently reporting on a diversity of self-selected incidents of bullying, had high concordance in their collective reports, $r(8)=.99, p<.001$.

Perceived causes of bullying. The victims' and witnesses' open-ended descriptions of bullying often mentioned what they thought were the causes of the 
incident, and these, almost without exception, made reference to characteristics of the victim. In this study, $25 \%$ of all victims and $18 \%$ of all witnesses mentioned external characteristics of the victim, including these categories (with respective percentages for victims and witnesses in parentheses): appearance and body type $(10 \%, 7 \%)$, regional identity $(10 \%, 5 \%)$, Norwegian accent $(5 \%, 5 \%)$, skin color $(0 \%, 2 \%)$, and gender (mentioned once by one witness). Furthermore, $11 \%$ of the victims and $23 \%$ of the witnesses mentioned internal characteristics of the victim as causes of bullying, including these categories (with respective percentages for victims and witnesses in parentheses): personality and body language $(9 \%, 9 \%)$, behavior $(1 \%, 6 \%)$, hygiene $(0 \%, 2 \%)$, incompetence $(0 \%, 2 \%)$, low intelligence $(0 \%, 2 \%)$, tastes in music $(1 \%, 1 \%)$, and opinions and attitudes $(0 \%, 1 \%)$.

Victims' and witnesses' explanations of bullying never made reference to the bullies' personality traits or to the bullies' motives. Perhaps this arises from beliefs that there is a typical victim personality but not a bully personality (Siann, Callaghan, Lockhart, \& Rawson, 1993). Not one comment described bully behavior in positive terms, for example, as leadership. Hazing was mentioned as the cause of bullying by $9 \%$ of the victims and $3 \%$ of the witnesses, again showing that bullying and hazing can be confounded. The remarkably strong agreement between victims and witnesses concerning the persons involved, the locations, and the types of bullying was considerably weaker concerning the causes of bullying. Victim-witness concordance on the causes of bullying dropped, $r(13)=.74, p<$ .01 . Whereas witnesses mentioned internal characteristics of the victim more than twice as often as did the victims themselves, victims more frequently mentioned their external characteristics as the cause of the bullying. These results are consistent with the FEA: We tend to attribute causation to individuals, especially to their internal characteristics, and observers tend do this more readily than the participants themselves (Ichheiser, 1949; Ross, 1977).

Hazing. Although hazing happened more frequently than bullying, it was still a minority phenomenon: A total of 158 (22\%) soldiers reported that they had been hazed, and $134(19 \%)$ reported that they had hazed others. Of those doing the hazing, $51 \%$ did it to someone in another unit, $28 \%$ to someone in their own unit, and $12 \%$ in their own and other units. Thus, hazing differs from bullying by the frequency with which it is done to strangers. Reports of being hazed correlated weakly with reports of being bullied, $r(684)=.13, p<.001$.

Of the total sample, $46 \%$ believed that most seniors in the military service hazed new recruits - a belief that was positively correlated with perpetrating hazing, $r(672)=.40, p<.001$, and with being hazed, $r(670)=.26, p<.001$, which were also correlated with each other, $r(674)=.30, p<.001$. This replicates Baier and Williams's (1983) finding in fraternity hazing and accords with the cognitive bias called the "false consensus effect," namely, that one's own behavior is considered more 
typical and acceptable than the behavior of others (Deutsch, 1989; Mullen et al., 1985). These findings also suggest that hazing has qualities of a cultural norm, at least within a subculture of soldiers; that is, senior soldiers may be modeling, or informally training recruits, on how to haze. Thus, lack of exposure to hazing may be a good predictor that soldiers will not engage in hazing themselves.

The open-ended descriptions of hazing incidents were coded into five post hoc categories. Of the total 158 soldiers who had been hazed, $62 \%$ described it as seniors addressing juniors with the derogatory expression syl, which means "greenhorn" in the Army, and 6\% mentioned seniors using their dog-tag chain, called a dimmelenke, to display how many days remained until discharge. Of the total 134 soldiers reporting themselves as hazing others, $64 \%$ described it as saying syl to new recruits and $20 \%$ as using the dimmelenke. Physical acts, such as dumping water in a bed or binding recruits with tape, were mentioned by $19 \%$ of the soldiers who had been hazed and by $9 \%$ of those hazing others. Overall, victims of hazing and perpetrators of hazing had substantial concordance, $r(4)=.96, p<.01$, in their collective reports.

We might hypothesize that differences in victims' and witnesses' reports of physical hazing exist because it is more salient for the victims and, thus, easier for them to recall because those soldiers physically hazing others underreport it or because victims prefer to explain their victimization as hazing rather than bullying. For example, the most dramatic report of hazing, given by a victim, was "penis smeared with dishwasher detergent and caustic soda, repeatedly." However, by definition, this should not be termed an act of hazing because it could not be done to the whole cohort of recruits and could not be done publicly.

Friendships and leisure. Only $49(7 \%)$ soldiers reported that they had not had a friend during the first month of military service, and 10 of these soldiers were subsequently bullied, producing a weak but statistically significant correlation between friendlessness and victimization, $r(686)=.12, p<.01$. On the question of whom they spent leisure time with, $48 \%$ of the soldiers reported with a roommate, $56 \%$ with someone from their own troop, $19 \%$ with someone from their own unit, $10 \%$ with someone from another unit, and $1 \%$ alone. Spending leisure time alone was a correlate of being bullied, $r(645)=.29, p<.001$. Thus, social isolation is possibly a cause or a consequence of bullying.

Assignment practices. The Norwegian Army's new practice of unit replacement allows cohorts of recruits to stay together for the entire duration of their military service. The data show that unit replacement has had little effect on hazing but causes an increase in bullying as compared to the old practice of individual assignment of recruits after basic training. Reports of soldiers hazing others were un- 
changed at 20\%, $t(631)=0.16, p=.88$. Reports of victims being hazed decreased insignificantly from $26 \%$ in units using individual replacement to $21 \%$ in units based on cohorts, $t(633)=-1.33, p=.18$. However, with the new cohort practice, $13 \%$ of soldiers reported being bullied, compared to $10 \%$ in the units using individual replacement, $t(644)=1.07, p=.29$, and $57 \%$ of soldiers in the cohort system had witnessed bullying, compared to $45 \%$ under the old practice, $t(644)=2.79, p<.01$. Particularly worrisome is the finding that $36 \%$ of soldiers in cohort units reported witnessing bullying during field maneuvers, compared to only $24 \%$ in units with individual replacement, $t(322)=2.01, p<.05$.

These findings may be due to less group cohesion in the cohort units: $15 \%$ of the soldiers compared to $7 \%$ in the old practice reported spending their leisure time alone or with people from other units, $t(600)=2.74, p<.01$. Another explanation may be that individual assignment of soldiers to different units disrupts familiarity, which apparently is a necessary condition for bullying. Or, perhaps it is less easy to mislabel bullying as hazing when there are no senior soldiers present in the unit to make that explanation plausible.

High-risk groups. Only $5(1 \%)$ soldiers were 18-year-olds, but this group seems to be particularly vulnerable for victimization in the Norwegian Army: $40 \%$ of them were bullied, $80 \%$ of them witnessed bullying, $40 \%$ of them were hazed, but $0 \%$ of them hazed others. Comparable figures for 19 -year-olds were $12 \%, 52 \%$, $26 \%$, and $21 \%$, respectively, and figures for older age groups were similar to the 19-year-olds. If 18 -year-olds are removed, then the correlations between age and the measures of victimization are all near zero but are all negative: For being bullied, $r(673)=-.06, p=.15$; for witnessing bullying, $r=-.04, p=.31$; for being hazed, $r(661)=-.06, p=.09$; and, interestingly enough, for hazing others, $r(660)=$ $-.08, p=.05$. That is, it tends to be younger soldiers, but not 18 -year-olds, who do the hazing.

Only $6(1 \%)$ soldiers lacked a friend in the first month of service and continued to spend leisure time alone. All of them were bullied, and 4 of them were hazed. None of these 6 isolated soldiers were 18-year-olds, and social isolation was completely independent of age, $r(622)=.02, p=.71$. Other studies of bullying have found social isolation to be a risk factor (Boulton \& Underwood, 1992; Olweus, 1993). However, because $87 \%$ of the bullied soldiers did have friends during the first month of service, and $89 \%$ of them did spend their leisure time with friends, social isolation only accounts for a minority of victims.

Female soldiers might be another high-risk group, although an examination of that deserves separate study because of the need for definitions and measurements that differentiate sexual harassment from bullying and hazing. In a study of a U.S. Army sample, Rosen and Martin (1999) reported that 30\% of the women and 8\% of the men felt themselves to have been sexually harassed. In contrast, the study re- 
ported here found that only $1 \%$ of the victims of bullying described the incident as sexual harassment. The 14 female soldiers in this study were indistinguishable from their male colleagues in measures of being bullied, $t(678)=-1.13, p=.26$; of witnessing bullying, $t(678)=-0.33, p=.74$; of being hazed, $t(666)=1.40, p=.16$; and of hazing others, $t(664)=0.50, p=.62$. The apparently different findings between this study and Rosen and Martin's study may be due to the fact that Norway is a much less sexist society than the United States (Hofstede, 1980).

\section{STUDY 2}

\section{Purpose}

The first author was invited back to the military base for a management workshop to give a presentation of the findings of Study 1 . Study 2 was conceived and executed to gather further information about bullying for presentation to Army officers attending that workshop. Study 2 was thus smaller, less elaborate, and less exploratory than Study 1. Whereas Study 1 had a focus on the physical and social contexts of bullying in the Army, Study 2 was more focused on the cognitive contexts of bullying. The goal was to begin a phenomenologically descriptive account of beliefs about bullying and, specifically, to display how soldiers and officers have similar or different beliefs and how those beliefs affect the readiness of individuals from either group to intervene in incidents of bullying.

\section{Method}

Instrument. A one-page questionnaire, written in Norwegian, was developed in two versions: one for soldiers and one for officers. The first 17 items were statements of beliefs about bullying, to be answered on a 6-point Likert scale ranging from X (disagree completely) to X (agree completely). As in Study 1, a formal definition of bullying was not imposed on the respondents. English translations of these items appear in Table 1. Items 18 and 19 were true-false questions asking whether respondents had witnessed bullying in their military unit and, if so, if they had intervened. The questionnaire form given to soldiers had one extra question: "If they themselves had been bullied, did an officer intervene?"

Procedure. The questionnaires were distributed by administrative military staff to approximately 100 soldiers and 100 officers of various ranks at the military base in Bardufoss, Norway. The use of military staff to distribute and collect the questionnaire may have introduced bias into the sample. Because logistic limita- 
TABLE 1

Soldiers' and Officers' Beliefs About Bullying

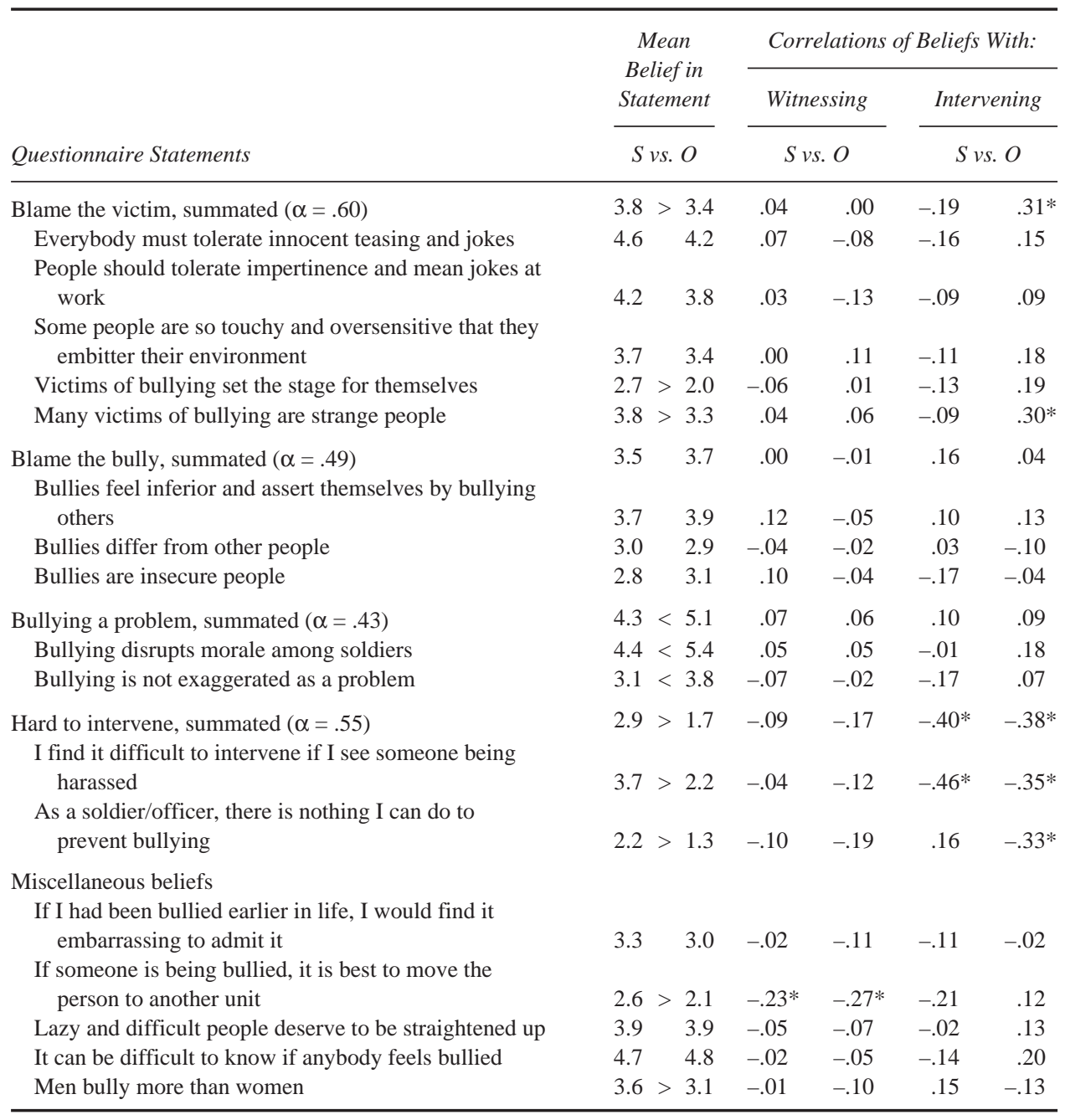

Note. Scores below 3.5 indicate disbelief, and scores above 3.5 indicate belief. Greater than and less than signs denote statistically significant differences $(p<.05$, two-tailed) between soldiers and officers. $\mathrm{S}=$ soldiers; $\mathrm{O}=$ officers.

$* p<.05$. 
tions precluded the use of return envelopes, anonymity was a concern. To give respondents some degree of privacy, however, they were not asked to identify themselves by name, unit, rank, age, or gender.

Sample. A total of 88 soldiers and 77 officers answered the questionnaire, for an overall return rate of approximately $80 \%$. This rate was higher than in Study 1 , possibly due to coercive pressures caused by reduced anonymity. Because Study 1 and Study 2 were sufficiently separated in time, they had no participants in common.

\section{Results and Discussion}

Prevalence. Only 4 (5\%) soldiers reported that they had been bullied in the Army, and 3 (75\%) of them reported that officers had intervened. A total of 63 (72\%) soldiers and $50(65 \%)$ officers reported that they had witnessed bullying. Of these, $12(19 \%)$ soldiers and $43(86 \%)$ officers reported that they had intervened.

Beliefs. As shown in Table 1, the questionnaire statements about bullying could be grouped into four themes based on meanings and intercorrelations: (a) blame the victim, (b) blame the bully, (c) bullying is a problem, and (d) hard to intervene. There was also a set of five miscellaneous beliefs. To simplify the presentation of findings, composite index scores for the first four of these were computed. Among items in an index, there were no negative interitem correlations, and Cronbach's alpha coefficients were high considering that the indexes had only five, three, two, and two items, respectively.

Beyond this simple grouping by meaning, data reduction was not pursued. In particular, factor analysis was not used because there are multiple correct factor solutions and multiple ways to rotate and label factors, all dependent on the interpretive preferences of the authors. Factor analysis and other multivariate procedures would, thus, violate the descriptive, phenomenological intent of this study. If readers wish to consider only the analyses of the individual questions, and not the grouped scores, that information is presented in Table 1. The findings and discussion are essentially unchanged either way.

In Table 1, the columns on the left-hand side display mean measures of belief in each item separately for soldiers and officers. The columns of numbers on the right-hand side display the relations between beliefs and witnessing bullying and the relations between beliefs and intervening in bullying. Table 1 displays 84 correlation coefficients and might be criticized for inflating Type I error. However, Bonferroni-type adjustments were not pursued because significant findings were always replicated across questions or across samples, thus discounting concern that significance was a random event.

As shown in Table 1, soldiers consistently tended to blame the victim more than did the officers; however, neither group consistently blamed the bully. Not shown 
in Table 1, the 4 victims of bullying had a summated blame-the-victim score ( $M=$ 2.6, $S D=0.24$ ), which was significantly lower, $t(86)=3.29, p<.001$, than the summated score for the other soldiers $(M=3.9, S D=0.08)$. Considering that the scale midpoint was 3.5, victims did not believed that victims are to blame for bullying, and those who had not been bullied did believe that victims are to blame.

Soldiers and officers believed that bullying is a problem-officers more so than soldiers. Among soldiers, victims believed that bullying is a problem $(M=5.8, S D$ $=0.25)$ more, $t(87)=-2.67, p<.01$, than did other soldiers $(M=4.2, S D=0.12)$. Soldiers and officers rejected the idea that it is difficult to intervene, with officers rejecting this very strongly. Both groups tended to reject ideas that bullying is embarrassing for victims and that it is best to transfer victims out of the unit. Both groups accepted the idea, however, that lazy and difficult people deserve punishment. Both groups strongly agreed that it is difficult to know if someone feels bullied. Officers rejected the idea that bullying is a male behavior.

Sources of beliefs. As shown in Table 1, in the center two columns of numbers, beliefs uniformly had near-zero correlations with witnessing bullying — with one exception. Thus, beliefs are independent of observations. This suggests that beliefs about bullying are not being shaped by observed reality but by other cognitive or enculturative processes. The one exception was that soldiers and officers replicated the negative correlation between witnessing bullying and believing that victims should be transferred out of the unit, $r(84)=-.23, p<.05$, and $r(76)=-.27, p<$ .05 , for soldiers and officers, respectively. That is, witnesses of bullying tend to believe that victims should not be transferred, but people who had not witnessed bullying tend to believe that victims should be transferred.

Intervention. On the far right-hand side of Table 1 are the correlations of beliefs and intervention behavior. For all five beliefs that blame the victim, and for their summation, soldiers showed consistently negative correlations with intervening, whereas officers showed consistently positive correlations with intervening, most strongly for the summated measure, $r(54)=.31, p<.05$. It should be noted that neither pattern of correlations works well for the victims of bullying: Soldiers who blame the victims let them suffer the bullying, and officers who blame the victims intervene but blame the victims for the incident. Beliefs that bullies are to blame and beliefs that bullying is a problem had no effects on intervention behavior. Rather, the strongest and most consistent predictor of intervention is rejection of beliefs that effective intervention is difficult, seen most strongly in the summated measure for the soldiers, $r(72)=-.40, p<.001$, and for the officers, $r(54)=-.38, p<.01$.

Corrected prevalence. In total, 50 (56\%) soldiers agreed that it would be embarrassing to admit to being bullied-a feeling that might inhibit self-reports, especially in contexts of reduced anonymity, such as in this study. None of the 29 
(33\%) soldiers who answered "completely agree" or "quite agree" to the embarrassment question admitted to being bullied. The reluctance of victims to report themselves can be quantified, and the group data can be statistically corrected. A corrected prevalence rate can be estimated by employing discriminant analysis to determine how many soldiers answered their questionnaires like a victim even though they did not declare themselves to be a victim. Using all questionnaire items to predict self-report of victimization, the computed discriminant function correctly identified $100 \%$ of the questionnaires belonging to victims and $90 \%$ of the questionnaires belonging to soldiers claiming not to be victims. The discrepant $10 \%$ consisted of 7 soldiers. If they are counted as victims who declined to report themselves as victims, then not 4 soldiers, but 11 , were bullied, for a corrected prevalence rate of $12 \%$.

\section{SUMMARY DISCUSSION}

\section{Replicated Prevalence}

Studies have shown that the prevalence of bullying can be accurately estimated from self-report data (Connell \& Farrington, 1997). However, overreporting and underreporting are concerns. The two studies presented here did not impose a definition of bullying on the respondents; therefore, some reports of bullying ( $2 \%$ or $3 \%$ in Study 1) referred to acts of hazing. Without a definition, people might also report one-time incidents as bullying, which would not be in accordance with some formal definitions (e.g., Olweus, 1992). Studies have shown that participants and observers of bullying can define bullying to be a single event (Madsen, 1996; Smith \& Levan, 1995) as do some theorists (Craig \& Pepler, 1997).

Underreporting has numerous causes. Acts of bullying may be downplayed and dismissed as not worth reporting, especially considering that nonchalance is a common strategy victims adopt to diminish or stop bullying (Salmivalli, Karhunen, \& Lagerspetz, 1996). For example, 1 soldier commented: "But I did not feel offended." Underreporting can also happen if bullying is misperceived and misreported as hazing, as demonstrated in Study 1. Underreporting also happens if victims had been removed from the population at some time prior to the study. Soldiers having serious difficulties in the Army are frequently given early discharge (Rapp, 1997).

Finally, it seems that lack of confidentiality tends to reduce self-reports of bullying. To date, there have been three studies of the prevalence of bullying in the Norwegian Army. Each had a different degree of confidentiality, and each found a different prevalence rate. Study 1 involved no face-to-face interviews, no record of the participants' names, and no exposure of the questionnaires when they were collected. Study 1 found $12 \%$ of soldiers reporting themselves bullied. Hytten and 
Tande's (1985) study used face-to-face interviews and promises of confidentiality, resulting in a prevalence rate of $8 \%$. Study 2 involved no face-to-face interviews and no record of the participants' names or other identifying characteristics, but it did compromise confidentiality during the open return of questionnaires via Army staff, resulting in a prevalence rate of $5 \%$.

However, if the prevalence rate for Study 2 is corrected by counting those 7 soldiers as victims who answered the questionnaire in the same pattern as declared victims did, then $12 \%$ of the soldiers can be counted as having been bullied in the Army. This replicates the $12 \%$ prevalence rate found in Study 1. Hytten and Tande's (1985) $8 \%$ prevalence rate is within the normal range of sampling error for the $12 \%$ rate, $z(696)=1.85, p>.05$, and $z(88)=1.85, p>.05$ Thus, a conservative conclusion, replicated across three studies using three different methods, would be that the prevalence of perceived bullying victimization in the Norwegian Army is $12 \%$. The prevalence of bullying in the Norwegian Army is, therefore, quite comparable to its prevalence in other Norwegian institutions. For example, a summary review of bullying in Norwegian public schools concluded that the prevalence rate was 9\% (Olweus, 1997), and a summary review of bullying in Norwegian workplaces, both private and public, found a 9\% prevalence rate (Einarsen \& Skogstad, 1996).

\section{Interventions}

The findings from these two studies do suggest plausible administrative interventions to reduce the prevalence or the negative impact of bullying and hazing in the Army. The following suggestions are tentative and, if implemented, should be tested or monitored for effectiveness by the use of pre- and postmeasures and by the use of control groups if possible:

1. Identify and attend to high-risk groups: The 18-year-olds, although comprising a minority of soldiers (1\%), suffered a high rate of bullying and hazing. It is not clear if this is due to unique vulnerability or merely to being the youngest on base. The big difference in prevalence between 18-year-olds and 19-year-olds and the lack of age effects above age 18, however, suggest that they are a unique group. If so, then removing 18-year-olds would not result in bullying shifting to the 19-year-olds. In addition to 18-year-olds, socially isolated soldiers are also at high risk for being bullied and hazed. Both groups are predictably going to have a punishing experience in the Army. Thus, delaying the induction of 18-year-olds should be considered, as should early discharge, without prejudice, of socially isolated soldiers.

2. Improve assessment of duty assignments: Perhaps another risk group are those soldiers whose competence or intelligence are lower than average. Norway practices universal military service and, thus, has recruits from the full range of na- 
tive intelligence and abilities. Even dismissing low IQ recruits, there will always be individuals at the low end. Approximately $4 \%$ of the witnesses' explanations of bullying mentioned incompetence and low intelligence, for example, "bullied for so many dumb mistakes while on duty." This accords with Olweus's (1973) findings in school systems. However, incompetence is relative to the demands of the tasks that the soldiers are assigned to perform. Assigning soldiers to tasks for which they are demonstrably incompetent impairs their unit's performance, frustrates comrades doing related duties, and thus increases the likelihood of bullying. Therefore, bullying could result from the Army's own administrative failings to assess abilities, assign appropriate tasks, and effectively train individual soldiers.

3 Make systematic use of superordinate goals: A task that benefits everyone and requires group coherence if it is to be achieved tends to cause positive attitudes among everyone involved, thus increasing group solidarity and decreasing interpersonal conflict (Sherif \& Sherif, 1969). Such tasks entail superordinate goals. The fact that bullying occurs during field maneuvers shows that superordinate goals in that setting are not effective in creating group cohesion. In fact, Deschamps and Brown (1983) argued that superordinate goals are most effective when participants enjoy distinctive and noncomparable roles. Thus, superordinate goals might become more effective for the Army if (a) each soldier's unique role was emphasized; and (b) superordinate goals were less episodic, that is, not limited to field maneuvers. The first point would be a matter of unit leadership, whereas the second point might be achieved, for example, by emphasizing the continuing superordinate goals of organizational effectiveness and of nation building. In the case of effectiveness, the presentation to the troops would be that "we have an important job to do" and that bullying damages morale, making everyone's job more difficult. In the case of nation building, the presentation would be that the Army serves to unify the nation and that bullying is divisive and unpatriotic.

4. Give more care to the design and management of barracks: Most bullying is done in the barracks, commonly by roommates. Eliminating bullying there would reduce the overall prevalence rate in the Army by $50 \%$ or more. The quality of barrack life might be enhanced by better administrative supervision, including designated leadership responsibilities by barrack residents, by routine training programs on roommate conflict resolution (Hardy, Orzek, \& Heistad, 1984; Waldo, 1984), and by restructuring barracks into double or single rooms to avoid the formation of several-against-one coalitions that arise when three or more soldiers share a room (Reddy, Baum, Fleming, \& Aiello, 1981). Unfortunately, there are no effective ways to match roommates for compatibility (Cary, Stanley, \& Biggers, 1988; Dodge, 1989; Pierce \& Schwartz, 1974; Wetzel, Schwartz, \& Vasu, 1979).

5. Educate soldiers about bullying: If soldiers were made conscious of the contexts of bullying and of the common misbeliefs that justify bullying, then they might gain insight about themselves and have some better possibility of acting re- 
sponsibly (Lewin, 1951/1997a). The troops can be informed as to what actions constitute bullying, where it is likely to occur, who is likely to be the bully, and how bullying differs from hazing. They can also be told that approximately one third of all soldiers have been bullied earlier in life and that it was not their personality, looks, habits, or other personal traits that caused them to be victims, even though we all have a natural bias to think that that is true. Soldiers should also be warned about tendencies to rationalize bullying as hazing and to blame the victim.

6. Instruct officers about bullying: It is important that administrative authorities and group leaders display their disapproval of bullying (Olweus, 1994, 1997). Officers should be instructed on the negative effects of bullying on the victim, the bully, the unit, and the Army in general. As with the soldiers, the officers can be taught the contexts and psychological dynamics of bullying, including the myths that sustain it.

7. Regulate hazing: Hazing is a very common, if not universal and inevitable, behavior in institutions like the Army. However, hazing and bullying should not be confused with one another even though that is easy to do. The Norwegian Army's new unit replacement practice, like the U.S. Army's earlier COHORT experiment (Vaitkus \& Griffith, 1990), has not had the positive effects on unit cohesion that were expected, possibly because policy planners confused bullying and hazing. Their expectation that social cohesion among recruits would improve if they were segregated from senior soldiers presumes that hazing by senior soldiers is bullying and is the cause of poor cohesion. This overlooks not only the value of the senior soldiers' leadership skills but also the value of hazing for group cohesion when hazing is sharply differentiated from bullying.

Hazing serves social and cultural functions (Winslow, 1997) and is remarkably resistant to efforts to ban it (Anderson \& Noesjirwan, 1980; Baier \& Williams, 1983; Cuche, 1985; Lenny, 1949), especially by top-down directives (Brown, 1976). If the rituals of basic training — for example, shaved heads—are considered to be institutional initiations, then the Army is, and always has been, engaged in the hazing of new recruits. Further formalizing of hazing might be one way to differentiate it from bullying and thereby reduce the prevalence of bullying. This would require specifying the veteran cohort who will do the hazing, the recruit cohort who will be hazed, the acts of hazing that will be allowed, the locations where hazing will occur, the duration of hazing, and the ceremony or celebration welcoming the recruits into full membership in the unit. Acts of hazing should always be directed against groups of recruits and never at isolated individuals. Acts of hazing should be restricted to activities that serve the Army's and the recruits' long-term interests, especially anything that orients the recruits to understand and move within their new physical and social "field" (Lewin, 1951/1997a). For example, hazing might be restricted to the dining room and might include making recruits recite their chain of command, name all of their barrack mates, sing unit songs, or answer questions about unit history. Formalizing hazing would essen- 
tially be an exercise in cultural engineering and should be undertaken, if at all, with anthropological advisement.

\section{Theories of Bullying}

This research was exploratory and phenomenologically descriptive. The studies began without, and ended without, an explicit theory of bullying. However, some of the findings do inform or constrain theories of bullying.

1. Contrary to beliefs and theories that follow the FEA, the enduring physical, dispositional, or behavioral traits of the victim are not sufficient to explain bullying. Study 1 found that victimization does not transfer to different contexts. Olweus (1993) and Rivers and Soutter (1996) found similar results and concluded that there are no "natural victims." Olweus (1973) demonstrated that victims of bullying, in fact, do not differ from others on such factors as language, appearance, clothing, or intelligence.

2. Bullying is a function of familiarity, requiring that some or all of the people involved be familiar with each other. This would tend to argue against biological explanations of bullying because, among animals of various types, familiarity among individuals reduces aggression (Stookey \& Gonyou, 1998; Zumpe \& Michael, 1996). More plausible is the explanation that bullying requires the creation of a social network to support the bully, and that requires time and familiarity (Maines \& Robinson, 1998; Salmivalli, Huttunen, \& Lagerspetz, 1997; Salmivalli, Lagerspetz, Bjorkqvist, Osterman, \& Kaukiainen 1996).

3. Bullying is essentially a cognitive phenomenon, as shown by the findings that (a) perceptions follow the FEA, (b) beliefs are independent of observations, and (c) beliefs predict behaviors. This is very much in accord with Olweus's (1994) argument that bullying entails gradual collective cognitive changes in perceptions of bullies and victims.

\section{Future Studies}

The studies reported here require replication as well as extension-to other national armies and comparatively across national armies. The interventions proposed here, if implemented, would require control groups to evaluate effectiveness. Following Putnam's (1975) concerns about the relation between lay and expert definitions, studies of linguistic usage are needed to determine the meanings of bullying and hazing as well as sexual harassment and racism, for soldiers, officers, the public, and social scientists. Definitions of these phenomena should not be ex cathedra declarations by experts (Arora, 1996). As reliable and shared definitions 
of the various forms of interpersonal conflict are discovered, then, following Rosen and Martin's (1999) design, behavioral checklists or psychometric scales might be developed and validated. As part of the definitional discovery, and as part of the validation of scales, ethological studies modeled on that of Craig and Pepler (1997) might be extended to compare confirmed behaviors with immediate and retrospective accounts by the participants.

\section{REFERENCES}

Adams, A. (1992). Bullying at work. London: Virago Press.

Anderson, A. M., \& Noesjirwan, J. A. (1980). Agricultural college initiations and the affirmation of rural ideology. Mankind, 12, 341-347.

Arora, C. M. J. (1996). Defining bullying: Towards a clearer general understanding and more effective intervention strategies. School Psychology International, 17, 317-329.

Ashforth, B. (1994). Petty tyranny in organizations. Human Relations, 47, 755-778.

Baier, J. L., \& Williams, P. S. (1983). Fraternity hazing revisited: Current alumni and active member attitudes toward hazing. Journal of College Student Personnel, 24, 300-305.

Batsche, G. M., \& Knoff, H. M. (1994). Bullies and their victims: Understanding a pervasive problem in the schools. School Psychology Review, 23, 165-174.

Bersani, G., Nesci, D. A., \& Pozzi, E. (1980). Controllo sociale e sistema delle identificazioni in una istituzione totale: Il "nonnismo" in caserna [Social control and identification system in a total institutional environment: "Granddaddyism" in the Italian military barracks]. Lavoro Neuropsichiatrico, 67, 323-343.

Bivens, M. (1995, May). Look homeward, general. Modern Maturity, 38(3), 46.

Boulton, M. J., \& Underwood, K. (1992). Bully/victim problems among middle school children. British Journal of Educational Psychology, 62, 73-87.

Bowers, L., Smith, P. K., \& Binney, V. (1994). Perceived family relationships of bullies, victims and bully/victims in middle childhood. Journal of Social and Personal Relationships, 11, 215-232.

Brown, L. D. (1976, February 2). Organizational change from the bottom up. Education and Urban Society, 8, 159-171.

Burk, F. L. (1897). Teasing and bullying. Pedagogical Seminary, 4, 336-371.

Cary, J. C., Stanley, D. L., \& Biggers, J. (1988). Peak alert time and rapport between residence hall roommates. Journal of College Student Development, 29, 239-243.

Cermak, J. (1992). Role poddustojniku v CSA [The role of NCOs in the Czechoslovak Army]. Sociologia, 24, 166-170. (From Humanities Index, Sociofile: Hazing, 1997, Abstract No. 9302825)

Connell, A., \& Farrington, D. P. (1997). The reliability and validity of resident, staff and peer reports of bullying in young offender institutions. Psychology, Crime and Law, 3, 287-300.

Craig, W. M., \& Pepler, D. J. (1997). Observation of bullying and victimization in the school yard. $\mathrm{Ca}$ nadian Journal of School Psychology, 13, 41-59.

Cuche, D. (1985). Traditions populaires ou traditions elitistes? Rites d'initiation et rites de distinction dans les ecoles d'arts et metiers [Popular traditions or elitist traditions? Rites of initiation and rites of distinction in the schools of arts and vocations]. Actes de la Recherche en Sciences Sociales, 60, 57-67.

Cvrcek, J. (1992). K problematice mezilidskych [The problems of human relations in the Czechoslovak military]. Sociologia, 24, 145-152. (From Humanities Index, Sociofile:Hazing, 1997, Abstract No. 930226) 
Deschamps, J. C., \& Brown, R. (1983). Superordinate goals and intergroup conflict. British Journal of Social Psychology, 22, 189-195.

Deutsch, F. M. (1989). The false consensus effect: Is the self-justification hypothesis justified? Basic and Applied Social Psychology, 10, 83-99.

Dodge, S. (1989). The imprecise art of roommate matching: Sorting out pre-med majors, unicorn collectors, and "fluff chicks." Chronicle of Higher Education, 36, 29-30.

Dyomin, Y. (1998, February 4). A "division of deserters" is on the run. Current Digest of the Post-Soviet Press, pp. 15-16.

Einarsen, S. (1996). Bullying and harassment at work. Unpublished doctoral dissertation, University of Bergen, Norway.

Einarsen, S., Raknes, B.-I., Matthiesen, S.-B., \& Hellesoy, O. H. (1996). Bullying at work and its relationships with health complaints. Nordisk Psykologi, 48(2), 116-137.

Einarsen, S., \& Skogstad, A. (1996). Bullying at work: Epidemiological findings in public and private organizations. European Journal of Work and Organizational Psychology, 5, 185-201.

Fisher, L. (1995, February 6). The Airborne's fall: Ottawa kills the regiment but questions remain. Maclean's (108), 18-20.

Hardy, E., Orzek, A., \& Heistad, S. (1984). Learning to live with others: A program to prevent problems in living situations. Journal of Counseling and Development, 63, 110-112.

Heinemann, P. P. (1973). Mobbing: Gruppevold blant barn og voksne [Bullying: Group violence among children and adults]. Oslo, Norway: Gyldendal.

Hofstede, G. (1980). Culture's consequences. London: Sage.

Hytten, K., \& Tande, T. (1985). Mobbing i forsvaret: Erfaringer fra en pilotunders $\phi$ kelse $i$ brigaden [Bullying in the Army: Lessons from a pilot study]. Unpublished internal report, Office for Psychiatry (FSAN), Army Psychological Services, Bardufoss, Norway.

Ichheiser, G. (1949). Misunderstandings in human relations. American Journal of Sociology, 55(Suppl.), 1-67.

Lenny, J. J. (1949). Caste system in the American Army. New York: Greenberg.

Lewin, K. (1997a). Behavior and development as a function of the total situation. In D. Cartwright (Ed.), Field theory in social science: Selected theoretical papers (pp. 337-381). Washington, DC: American Psychological Association. (Original work published 1951)

Lewin, K. (1997b). Field theory and experiments in social psychology. In D. Cartwright (Ed.), Field theory in social science: Selected theoretical papers (pp. 262-278). Washington, DC: American Psychological Association. (Original work published 1939)

Leymann, H. (1987). Mobbing $i$ arbeidslivet [Bullying in the workplace]. Lund, COUNTRY: Friundervisningens Forlag.

Leymann, H. (1990). Mobbing and psychological terror at workplaces. Violence and Victims, 5(2), $119-126$.

Madsen, K. C. (1996). Differing perceptions of bullying and their practical implications. Educational and Child Psychology, 13, 14-22.

Maines, B., \& Robinson, G. (1998). The no blame approach to bullying. In D. Shorrocks-Taylor (Ed.), Directions in educational psychology (pp. 281-295). London: Whurr.

McCoy, A. W. (1995). "Same banana": Hazing and honor at the Philippine Military Academy. Journal of Asian Studies, 54, 689-726.

Mullen, B., Atkins, J. L., Champion, D. S., Edwards, C., Hardy, D., Story, J. E., \& Vanderklok, M. (1985). The false consensus effect: A meta-analysis of the 115 hypothesis tests. Journal of Experimental Social Psychology, 21, 262-283.

Olweus, D. (1973). Hakkekyllinger og skolebøller [Chopped chicken and school bullies]. Oslo, Norway: J. W. Cappelens Forlag.

Olweus, D. (1992). Mobbing i skolen [Bullying in the school]. Oslo, Norway: Universitetsforlaget. 
Olweus, D. (1993). Victimization by peers: Antecedents and long-term outcomes. In K. H. Rubin \& J. B. Asendorf (Eds.), Social withdrawal, inhibition, and shyness in childhood (pp. 315-341). Hillsdale, NJ: Lawrence Erlbaum Associates, Inc.

Olweus, D. (1994). Annotation: Bullying at school: Basic facts and effects of a school based intervention program. Journal of Child Psychology and Psychiatry, 35, 1171-1190.

Olweus, D. (1997). Bully/victim problems in school: Facts and intervention. European Journal of Psychology of Education, 12, 495-510.

Pierce, R. A., \& Schwartz, A. J. (1974). Value similarity and satisfaction in suite-type living arrangements. Journal of College Student Personnel, 15, 213-219.

Power, K. G., Dyson, G. P., \& Wozniak, E. (1997). Bullying among Scottish young offenders: Inmates' self-reported attitudes and behavior. Journal of Community and Applied Social Psychology, 7 , 209-218.

Putnam, H. (1975). The meaning of “meaning." In K. Gunderson (Ed.), Language, mind and knowledge. Minnesota studies in the philosophy of science (Vol. 7, pp. 131-193). Minneapolis: University of Minnesota Press.

Quine, L. (1999). Workplace bullying in NHS Community Trust: Staff questionnaire survey. British Medical Journal, 318, 228-232.

Rapp, O. M. (1997, October 20). Trives i trengsel [Thriving in the crowd]. Aftenposten, p. 44.

Rayner, C. (1997). The incidence of workplace bullying. Journal of Community and Applied Social Psychology, 7, 199-208.

Rayner, C., \& Hoel, H. (1997). A summary review of literature relating to workplace bullying. Journal of Community and Applied Psychology, 7, 181-191.

Reddy, D. M., Baum, A., Fleming, R., \& Aiello, J. R. (1981). Mediation of social density by coalition formation. Journal of Applied Social Psychology, 11, 529-537.

Rigby, K., \& Slee, P. T. (1993). Bullying among Australian school children: Reported behaviour and attitudes toward victims. Journal of Social Psychology, 131, 615-627.

Rivers, I., \& Smith, P. K. (1994). Types of bullying behaviour and their correlates. Aggressive Behavior, 20, 359-368.

Rivers, I., \& Soutter, A. (1996). Bullying and the Steiner School ethos: A case study analysis of a group-centered educational philosophy. School Psychology International, 17, 359-377.

Roland, E., \& Munthe, E. (1989). Bullying. London: David Fulton.

Rosen, L. N., \& Martin, L. (1999). Incidence and perceptions of sexual harassment among male and female U.S. Army soldiers. Military Psychology, 10, 239-257.

Ross, L. (1977). The intuitive psychologist and his shortcomings: Distortions in the attribution processes. In L. Berkowitz (Ed.), Advances in experimental social psychology (Vol. 10, pp. 174-220). New York: Academic.

Salmivalli, C., Huttunen, A., \& Lagerspetz, K. M. J. (1997). Peer networks and bullying in schools. Scandinavian Journal of Psychology, 38, 305-312.

Salmivalli, C., Karhunen, J., \& Lagerspetz, K. M. J. (1996). How do victims respond to bullying? Aggressive Behavior, 22, 99-109.

Salmivalli, C., Lagerspetz, K. M. J., Bjorkqvist, K., Osterman, K., \& Kaukiainen, A. (1996). Bullying as a group process: Participant roles and their relations to social status within the group. Aggressive Behavior, 22, 1-15.

Schuster, B. (1996). Rejection, exclusion, and harassment at work and in schools. European Psychologist, 1, 293-309.

Sherif, M., \& Sherif, C. W. (1969). Social psychology. New York: Harper \& Row.

Siann, G., Callaghan, M., Glissov, P., Lockhart, R., \& Rawson, L. (1994). Who gets bullied? The effect of school, gender and ethnic group. Educational Research, 36(2), 123-134.

Siann, G., Callaghan, M., Lockhart, R., \& Rawson, L. (1993). Bullying: Teachers' views and school effects. Educational Studies, 19, 307-321. 
Slee, P. (1994). Situational and interpersonal correlates of anxiety associated with peer victimization. Child Psychiatry and Human Development, 25, 97-107.

Smith, P. K., \& Levan, S. (1995). Perceptions and experiences of bullying in younger pupils. British Journal of Educational Psychology, 65, 489-500.

Smith, P. K., \& Sharp, S. (1994). School bullying. London: Routledge.

Sodownik, A., \& Fok, K. (1997, March 23). Army hazing: Breaking “the wave.” Warsaw Voice, p. 4.

Stookey, J. M., \& Gonyou, H. W. (1998). Recognition in swine: Recognition through familiarity or genetic relatedness? Applied Animal Behavior Science, 55, 291-305.

Strassberg, Z., Dodge, K. A., Pettit, G. S., \& Bates, J. E. (1994). Spanking in the home and children's subsequent aggression toward kindergarten peers. Development and Psychopathology, 6, 445-461.

Sutton, J., Smith, P. K., \& Swettenham, J. (1999). Bullying and "theory of mind": A critique of the "social skills deficit" view of anti-social behavior. Social Development, 8, 117-127.

Vaitkus, M., \& Griffith, J. (1990). An evaluation of unit replacement on unit cohesion and individual morale in the U.S. all-volunteer force. Military Psychology, 2, 221-239.

Waldo, M. (1984). Roommate communication as related to students' personal and social adjustment. Journal of College Student Personnel, 25, 39-44.

Walsh, J. (1997, December 4). New model army: HR in the British army. People Management, 3, 22-27.

Walsh, J. (1998, October 15). Macho culture blamed for rise in workplace bullying. People Management, $4,13$.

Wetzel, C. G., Schwartz, D., \& Vasu, E. S. (1979). Roommate compatibility: Is there an ideal relationship? Journal of Applied Social Psychology, 9, 432-445.

Wilcox, A. (1997, October). Hazing is not a rite. U.S. Naval Institute Proceedings, (123), 35-37.

Williams, K., Chambers, M., Logan, S., \& Robinson, D. (1996). Association of common health symptoms with bullying in primary school children. British Medical Journal, 313(7048), 17-19.

Winslow, D. J. (1997). Rites of passage and group bonding in the Canadian Airborne. Unpublished manuscript, University of Ottawa, Canada.

Zumpe, D., \& Michael, R. P. (1996). Social factors moderate the effects of hormones on the sexual and aggressive behavior of macaques. American Journal of Primatology, 38, 233-261. 